\title{
Managing the onset of accelerated deformation in capital development at Agnew Gold Mine
}

\author{
CR Moulding Gold Fields Australia Pty Ltd, Australia \\ RM Stephenson AMC Consultants Pty Ltd, Australia \\ BJ Barsanti Gold Fields Australia Pty Ltd, Australia \\ DD Francis Gold Fields Australia Pty Ltd, Australia
}

\begin{abstract}
The Kim Lode at Waroonga Underground (Agnew Gold Mine) extracts ore using a longhole open stoping method. The orezone dips west at approximately $65^{\circ}$ and predominantly lies between a sandstone hanging wall contact and an ultra-mafic footwall.

The Waroonga Underground has recently seen an increase in levels of deformation associated with squeezing ground conditions, including bulging of the shoulders, walls and floor heave. This is commonly experienced in the oredrives during ore extraction. However, this type of deformation has since begun to migrate into capital long-term development in the lower levels of the mine, including the access drives and decline. This paper describes the methods of observations, monitoring, modelling, short and long term management methods used at Waroonga Underground for safe production 1,180 $\mathrm{m}$ below surface.

The driving mechanisms of the squeezing ground conditions can be attributed to large and small-scale structures, rock mass strength, rock stress orientation, mine design, and the stoping sequence. The majority of the ground deterioration is between the Thresher and Spinner faults in the southern access drives. The rock mass between these faults and the orezone creates a 'triangle' of accelerated ground squeezing (within 24 hours of blasting). These mechanisms are discussed in relation to the results of non-linear numerical modelling and analysis using damage mapping. The damage mapping was used to identify areas requiring upgraded ground support leading to a proactive approach to ground control.
\end{abstract}

The overall aim is to develop a better understanding of potential damage in relation to structures at depth, and improve future planning of capital development location and orientation relative to the orezone.

Keywords: accelerated ground squeezing, ground support

\section{Introduction}

Mining at depth can lead to particular rock mass responses that can affect the potential long-term stability and safe primary access to production ore fronts. These long-term issues are primarily associated with geological structures, intact rock strength, rock mass characteristics, stress at depth, stope dimensions and mine layout. Waroonga Underground has experienced challenges that correlate to all of these factors, especially within the Kim Lode. This mining area has complex structural conditions and since 2014 stoping fronts have retreated to central pillars. These factors have led to squeezing ground conditions in the hanging wall access drives, including wall and shoulder buckling/bulging combined with severe floor heave.

This drive deformation was previously being observed within the oredrives (Woolley \& Andrews 2015). Since the stoping fronts have continued to retreat over multiple levels the deformation has begun occurring in long-term capital development specifically hanging wall access drives and Kim Decline below the retreating level. 
The deformation became more apparent and was occurring in similar locations throughout multiple levels. A series of ground support and mine layout reviews were undertaken to attempt to understand the potential long-term implications of the ground movement and rate of deformation relative to future ore extraction. These reviews included non-linear modelling, damage mapping of development and seismic hazard modelling. The non-linear model provides an insight into areas of potential damage given the current mining sequence. Damage mapping provides an indication of the deterioration of the rock mass and ground support over a period of time and was used to identify future areas of rehabilitation in advance.

This paper presents an overview into the geological settings, stress influences, mine design and new practices implemented to safely extract the ore from the Kim Lode.

\section{$2 \quad$ Background}

Agnew Gold Mine is located $27 \mathrm{~km}$ west of Leinster, Western Australia, and is $100 \%$ owned by Gold Fields Australia Pty Ltd. Agnew Gold Mine comprises of two underground gold mines, Waroonga Underground and New Holland Underground. The Waroonga Underground mine lies on the western limb of the Lawlers Anticline, on the north side of the Norseman-Wiluna greenstone belt. The mine is situated within a westerly dipping sequence of sandstone known as the 'Scotty Creek' formation, which is on a margin with ultramafic conglomerate units.

The mining area known as Kim Lode is defined by a $2-7 \mathrm{~m}$ thick quartz breccia zone that dips at about $65^{\circ}$ and is situated predominantly along the Scotty Creek sandstone ( $\mathrm{Kg}$ ) and ultramafic conglomerate unit 3 (SKcU3) contact. The Edmunds Lode is similar to Kim Lode but hosted in the Edmunds sandstone (SKgU). In general, all stopes have an ultramafic footwall but the particular unit can vary from the SKcU2 or SKcU3 (Figure 1). These lodes are currently mined between 1,160 $\mathrm{m}$ and 1,260 $\mathrm{m}$ below surface.

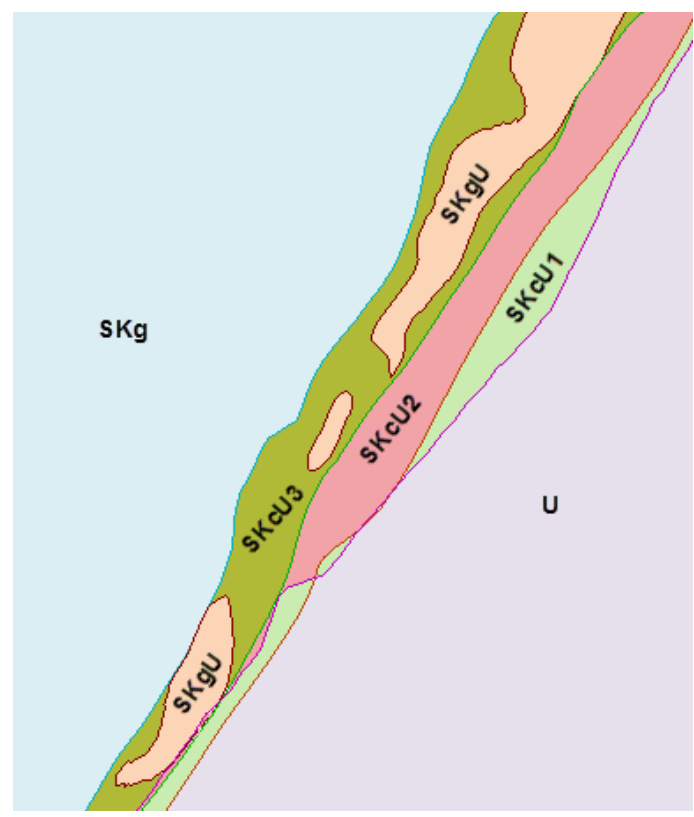

Figure 1 General cross-section of Waroonga lithology (looking north)

The mineralisation is hosted in two sub-parallel shears striking north-south. The dominant bedding in the Skg and ultramafic units ( $\mathrm{SkcU1}$, SkcU2, SkcU3) are orientated parallel to the oredrives, which is recognised to be a poor orientation and exacerbates squeezing ground conditions (Hadjigeorgiou et al. 2013).

The rock mass properties of both sandstone units (SKg and SKgU) and the SKcU3 consist of high rock-quality designation (RQD) values (greater than $90 \%$ ), intact rock strength of 140 to $220 \mathrm{MPa}$ and Q values of between 10 and 25. The weakest rock mass is the SKcU2, which has RQD value of $75 \%$, intact strength of $60 \mathrm{MPa}$, $Q$ value of six and has talc present along most joint planes. 
Complex cross-cutting fault structures and high mining-induced stresses are characteristic of the Kim Lode. These fault structures, along with the dominant bedding plane relative to the mine layout, greatly influence the location of squeezing ground conditions and the rate of deformation.

A typical level layout in Kim Lode has a central access from the Kim Decline, which is a 'cork screw' design. North and south ore fronts are accessed by a two hanging wall access drives from the central access, and referred to as North Access and South Access (shown in Figure 2). All this development is located in the Skg rock unit with the Kim Decline situated between 80 and $100 \mathrm{~m}$ into the hanging wall of the orezone. A similar design is replicated between levels with vertical pillars of between 12 and $15 \mathrm{~m}$.

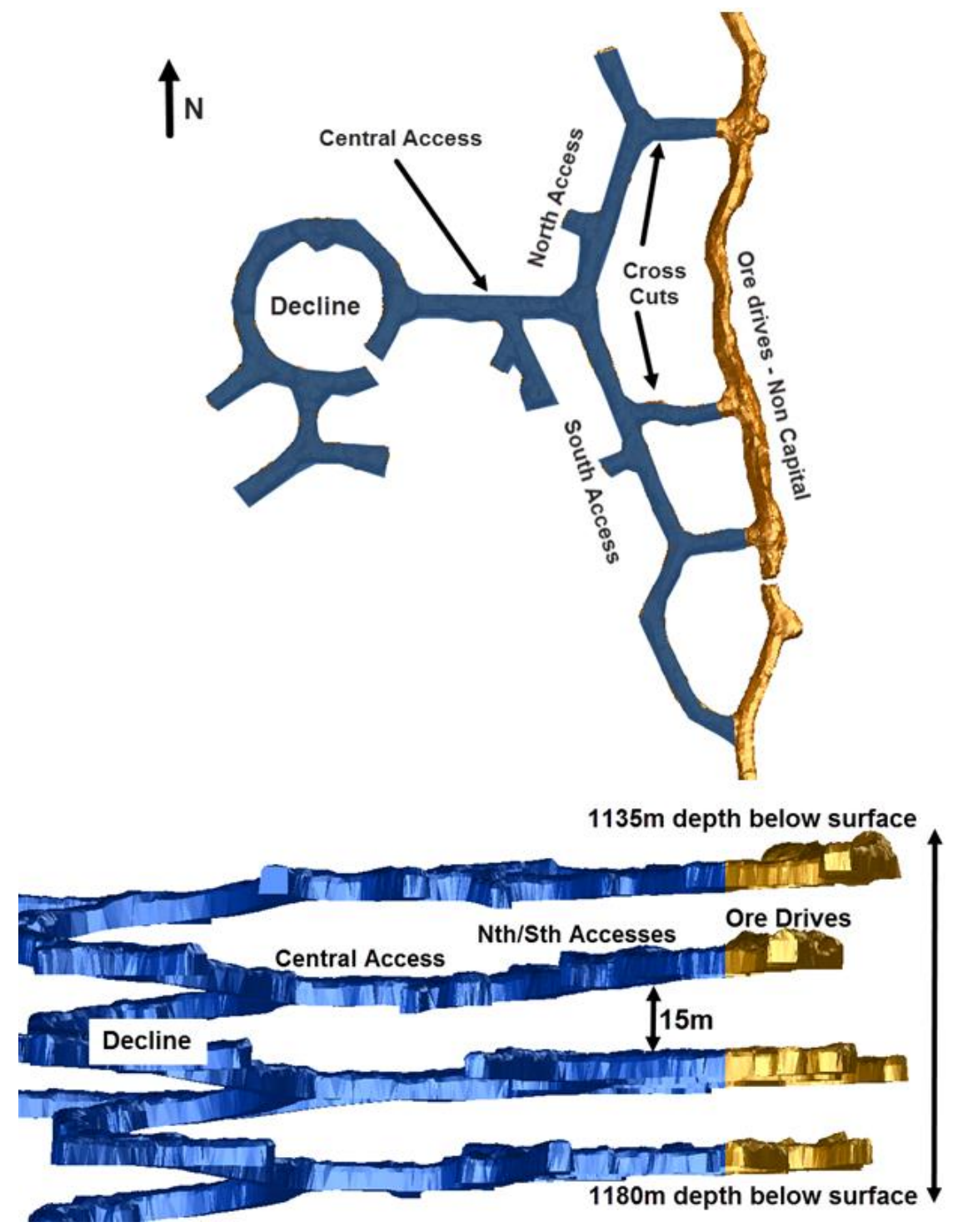

Figure 2 Plan view and cross-section (looking north) of typical level layouts. Outlined areas in blue indicate capital development

Ground support for the capital development at 1,180 m below surface was primarily $32 \mathrm{MPa}$ fibrecrete with a thickness of $50 \mathrm{~mm}$, sprayed to $1.5 \mathrm{~m}$ above the floor and $2.4 \mathrm{~m} 47 \mathrm{~mm}$ split sets spaced at $1.5 \mathrm{~m}$. Intersections are reinforced with $6 \mathrm{~m}$ twin-strand $50 \mathrm{t}$ fully grouted cable bolts. When squeezing ground behaviour became apparent in the capital access development, $6 \mathrm{~m}$ twin-strand cable bolts were installed in isolated sections of the hanging wall access drives.

By comparison, the primary ground support in oredrive development consisted of high-toughness fibrecrete (32 MPa $500 \mathrm{~J}$ mixture) from floor to floor, mesh installed across the backs down to $1.5 \mathrm{~m}$ above the floor, split sets and pattern cable bolting. 


\section{Observations}

As the mining fronts were retreating to central pillars, certain areas of capital development started to experience wall buckling, bulging, hanging wall shearing, substantial hanging wall floor heave and rock mass damage. Prior to 2016, this behaviour was observed to typically develop over the course of a few weeks beginning with isolated fibrecrete cracking in the shoulders and the split set plates being inverted. Spot rehabilitation was conducted as required to maintain stability and access. Since January 2016, the ground deformation began to accelerate (occurring within 24-72 hours of stope firings) and was not isolated to one specific location in development or level. Spot rehabilitation became inadequate, missing areas that would later deform and cause further production delays. Each pass of rehabilitation required the mine services (ventilation, air and water) to be removed adding to the time delays.

The lower areas of Kim Lode are intersected by three major fault structures known as Thresher, Spinner and Mako Faults. The Thresher Fault is a reactivated structure, which tends to increase deformation within oredrive development (Woolley \& Andrews 2015). All of these faults are sub-vertical, tightly healed and did not cause stability issues during initial development.

The level accesses intersected the faults with the access drives placed sub-parallel to the dominant north-south bedding. Due to the level layout, development intersections and pillars intersected these faults regularly. As stoping progresses, the rock mass between Thresher and Spinner Faults became damaged and was subjected to ongoing deformation and deterioration (Figure 3).

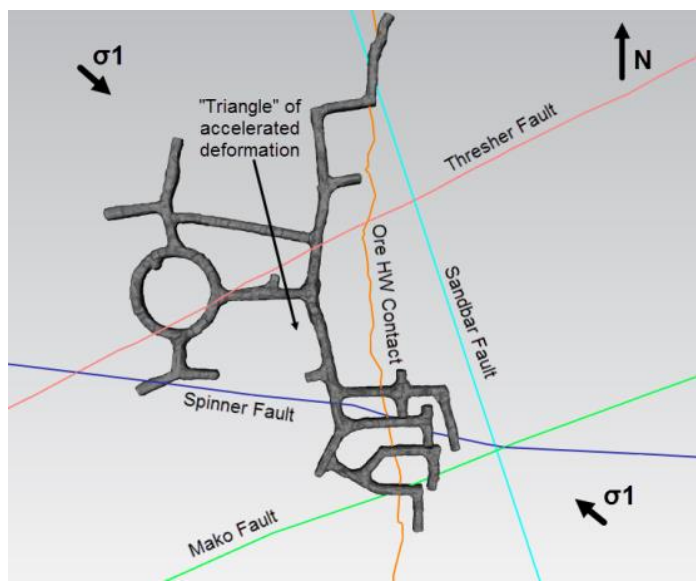

Figure 3 Fault structures and principal stress direction relative to mine design within Kim Lode

The spacing of the dominant bedding planes of the Skg unit within the capital development is variable, ranging between 0.05 and $0.5 \mathrm{~m}$. The thinly spaced bedding, along with deep-seated shearing, have been observed in the south access pillars at the ore front (cross cuts) as presented in Figure 4. This, combined with fault interactions, leads to the pillars becoming predisposed to deterioration and deformation if they are not supported adequately.

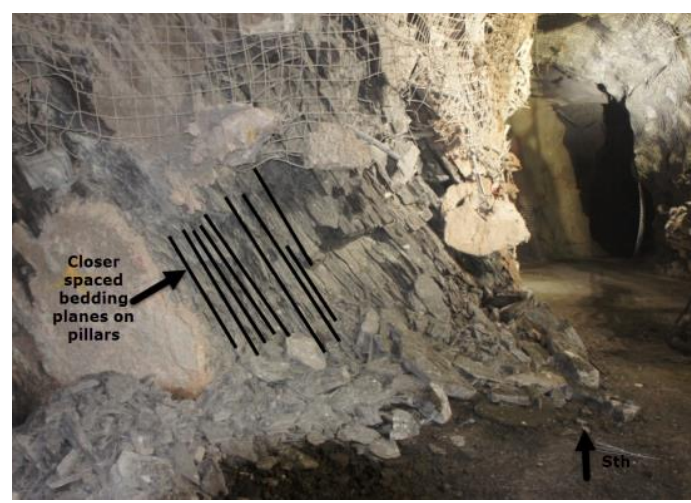

Figure 4 Closely spaced bedding on footwall (FW) pillars 


\subsection{In situ stress conditions}

The major principal stress direction $\left(\sigma_{1}\right)$ is oriented southeast-northwest and is horizontal. This is oblique to the dominant bedding plane and intersection pillars, and subparallel to the southern accesses. This causes the rock mass to converge in this orientation and load ground support elements.

The interpreted in situ stress field was determined by the Western Australia School of Mines using the acoustic emissions (AE) stress measurement technique. Measurements were completed on diamond drill core obtained from 292, 383, 745 and 1,147 m below surface. The measurements indicate a bi-linear trend, which indicates a major principal stress of $61 \mathrm{MPa}$ at $1,260 \mathrm{~m}$ below surface (Figure 5). This leads to a strength to stress ratio of 2.6 based on uniaxial compressive strength tests of the Skg unit. At these ratios of strength to stress the rock mass damage is expected to be high and will increase with depth.

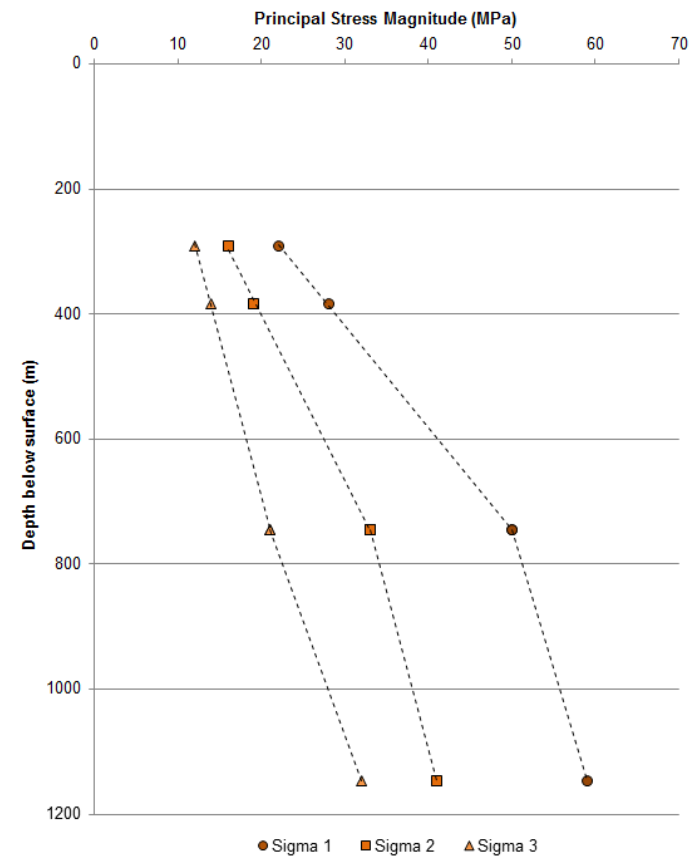

Figure 5 Acoustic emission results for in situ stress against depth below surface RL

The majority of rock mass damage was observed in the shoulders, lower walls and floor of the southern accesses (Figure 6). The depth of fracturing observed when probing and scaling these areas was up to $2 \mathrm{~m}$ in the backs and walls, and was broken up into 'shards' or thin planar slabs (spalling).
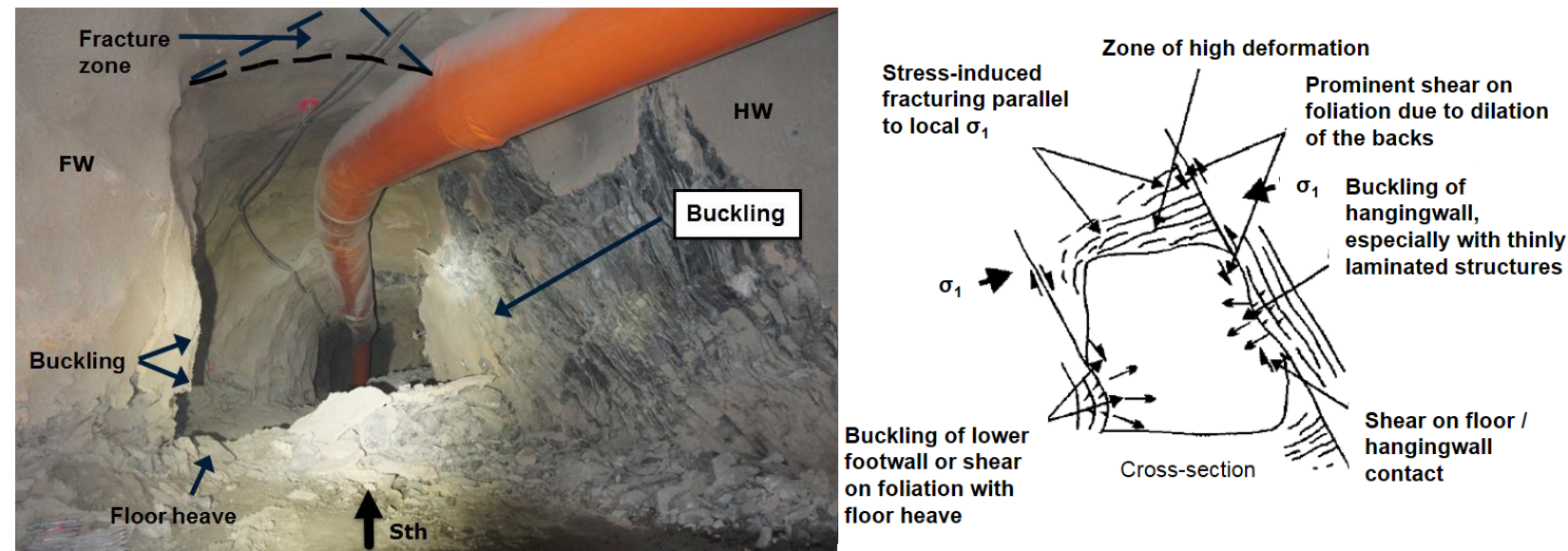

Figure 6 Southern access deformation at 1,200 m depth, relative to a diagram (Sandy et al. 2007) 
The majority of the deformation was occurring with the southern access drives and appeared to be accentuated between Thresher and Spinner Faults.

Survey monitoring is regularly used to quantify the extent of floor heave within the levels. Previous measurements have shown over $1.2 \mathrm{~m}$ heave in the eastern floor of the access drives (Figure 7). Stripping of the floor for machinery access encourages buckling in the lower eastern wall. This buckling material either falls out or is struck by a bogger, which leads to undercut walls and increases the span of the drive. Thereby, increasing loading to the support of the overhanging rock mass in the upper wall.

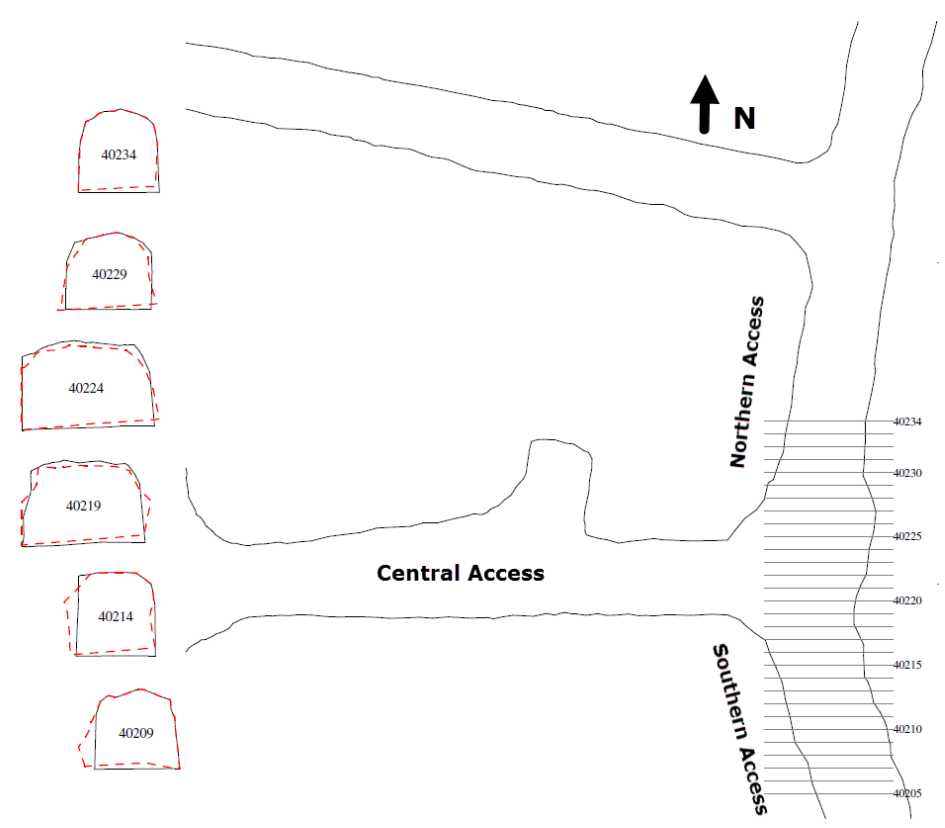

Figure 7 Example of floor heave monitoring in the capital accesses; original development represented by solid line and post deformation survey represented by dashed line

\section{$4 \quad$ Ground support performance}

The primary ground support for capital development was suitable for initial development, however, the support became unsuitable once squeezing behaviour was observed. Multiple passes of rehabilitation were required at this stage.

Support damage was observed in lower wall buckling below the fibrecrete, cracking and separation of fibrecrete that occurred between bolts, and shearing of split sets and plates being inverted into the rock mass (Figure 8).
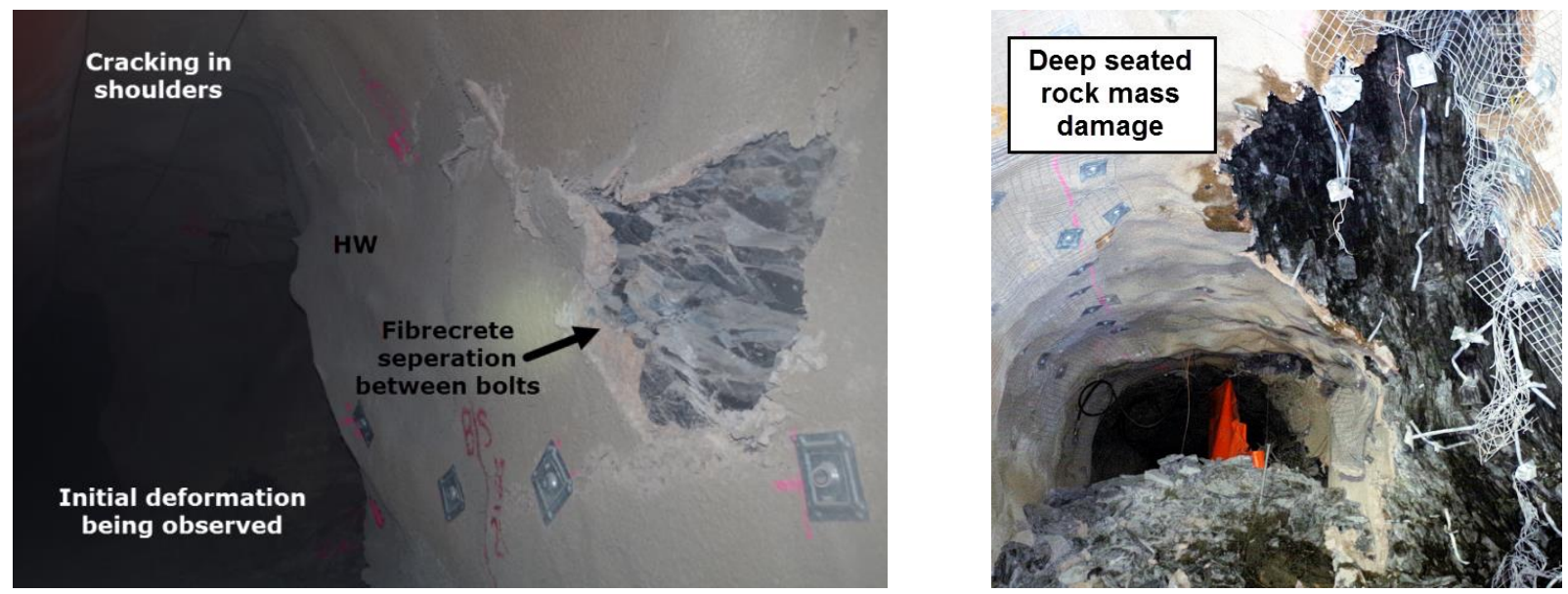

Figure 8 Example of initial deformation occurring and the increased rock mass damage after stope firings 
The split sets were compromised by the shearing of the hanging wall and the excessive loading due to drive convergence. The fibrecrete alone was too brittle and was unable to respond to the amount of deformation. With the surface support separating between the split sets, the spacing of reinforcement in the backs was too great for long-term stability.

The ground support damage was also identified to be, in part, compromised due to equipment damage. This included damaged or removed support around pillars and at approximately $1.5 \mathrm{~m}$ above the floor from bogger bucket scraping. This essentially removes one of the bolts confining the rock mass on the walls and weakens or wears down the fibrecrete support.

\section{$5 \quad$ Modelling and analysis}

\subsection{Damage mapping}

Closure monitoring was conducted using extensometer pins, survey pickups, and photo monitoring. The pins were largely unsuccessful in the lower Kim Lode levels on account of being damaged shortly after installation. Survey pickups are sporadic and conducted at low accuracy, and photo monitoring was not qualified against levels of damage. In lieu of instigating a new method of closure monitoring using laser techniques, regular damage mapping was instigated to quantify rates of deformation and estimate rehabilitation requirements. Damage mapping was also used to assist with numerical model calibration.

The adopted damage scale used for damage mapping was modified from Sandy et al. 2010. Photos from Kim Lode were used to describe examples of damage (Figure 9). The scale was related to the numerical model, constructed by Beck Engineering Pty Ltd.

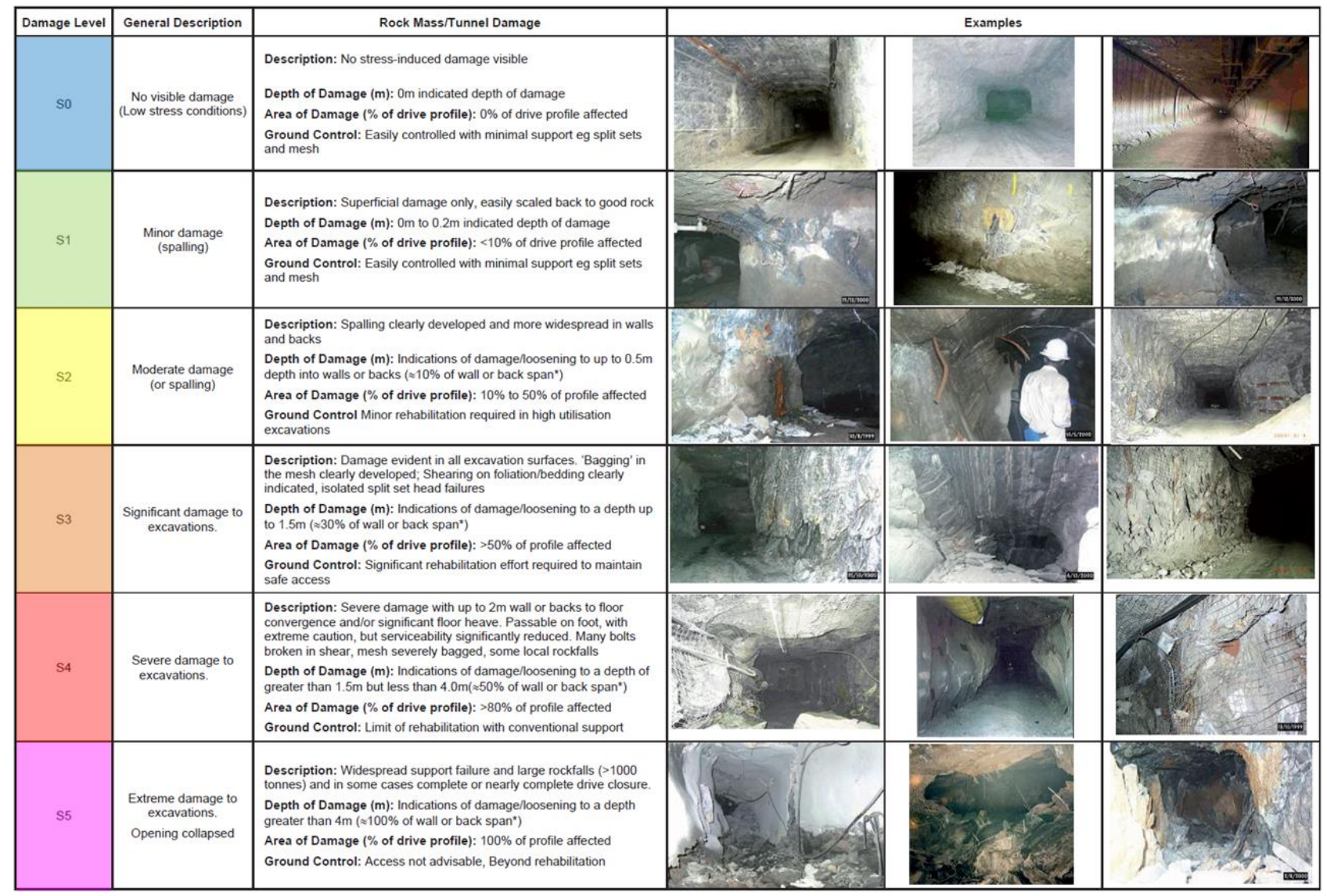

Figure 9 Damage scale (Sandy et al. 2007) adopted at Waroonga Underground 
Damage mapping is conducted periodically, whenever changes to damage in development are observed (Figure 10). The mapping is digitised using the mine asbuilts, which can be spatially compared with faults and numerical modelling results. The intention is to relate increases of damage to the response to stoping and forecast rates of damage and rehabilitation requirements.

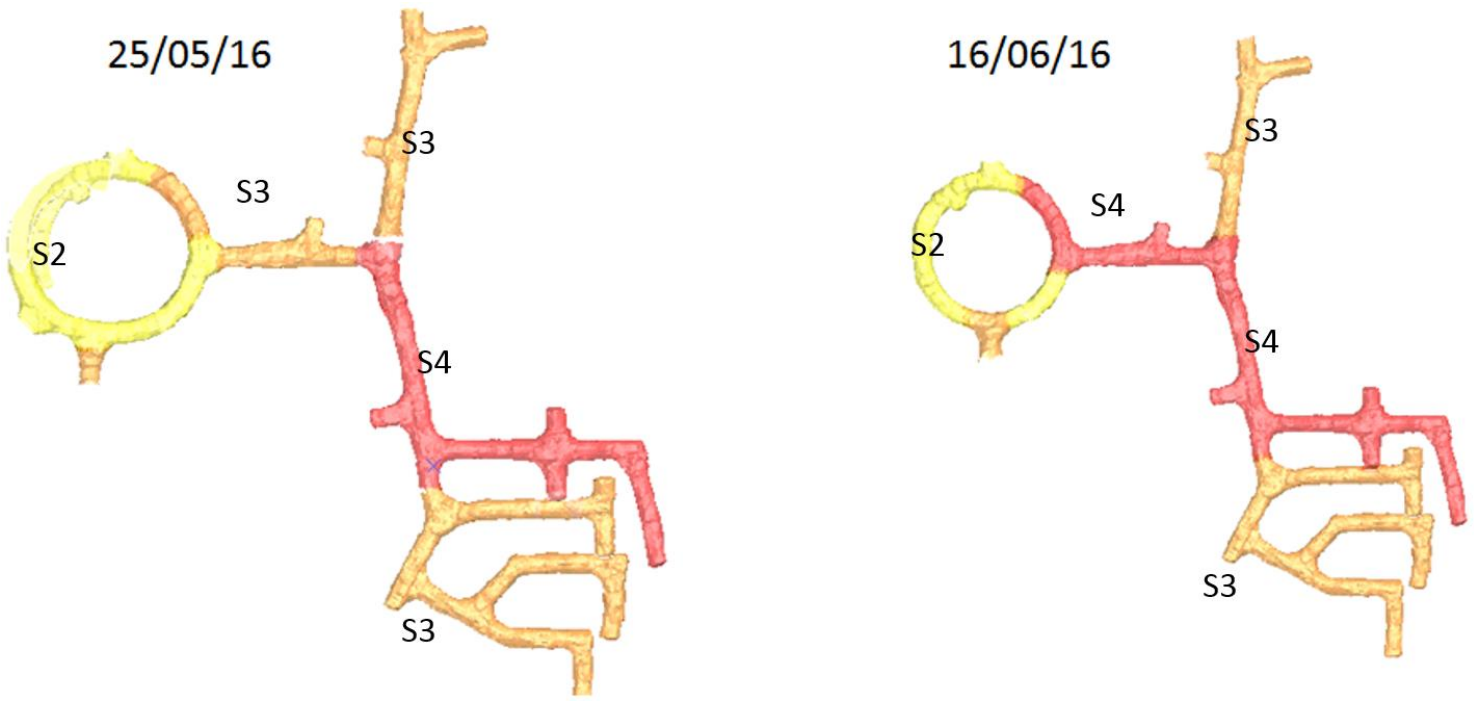

Figure 10 Progression of damage mapping of 260 Level across two different months

\subsection{Numerical modelling}

Numerical modelling was conducted by Beck Engineering Pty Ltd (Jones 2016) using elasto-plastic methods. The model was calibrated using a semi-quantitative approach including rock mass damage mapping, rock property testing and underground observations.

Following several iterations, the modelled damage for the 260, 240, and 200 Levels showed a reasonable correlation between simulated and modelled damage (Jones 2016), an example of this is shown in Figure 11. The damage mapping is indicated by the coloured development wireframes while the simulated damage is shown by the contours and meshes on the development. This model was used to assess the severity of rock mass damage in the proposed mine design below the 200L, specifically in the capital development.

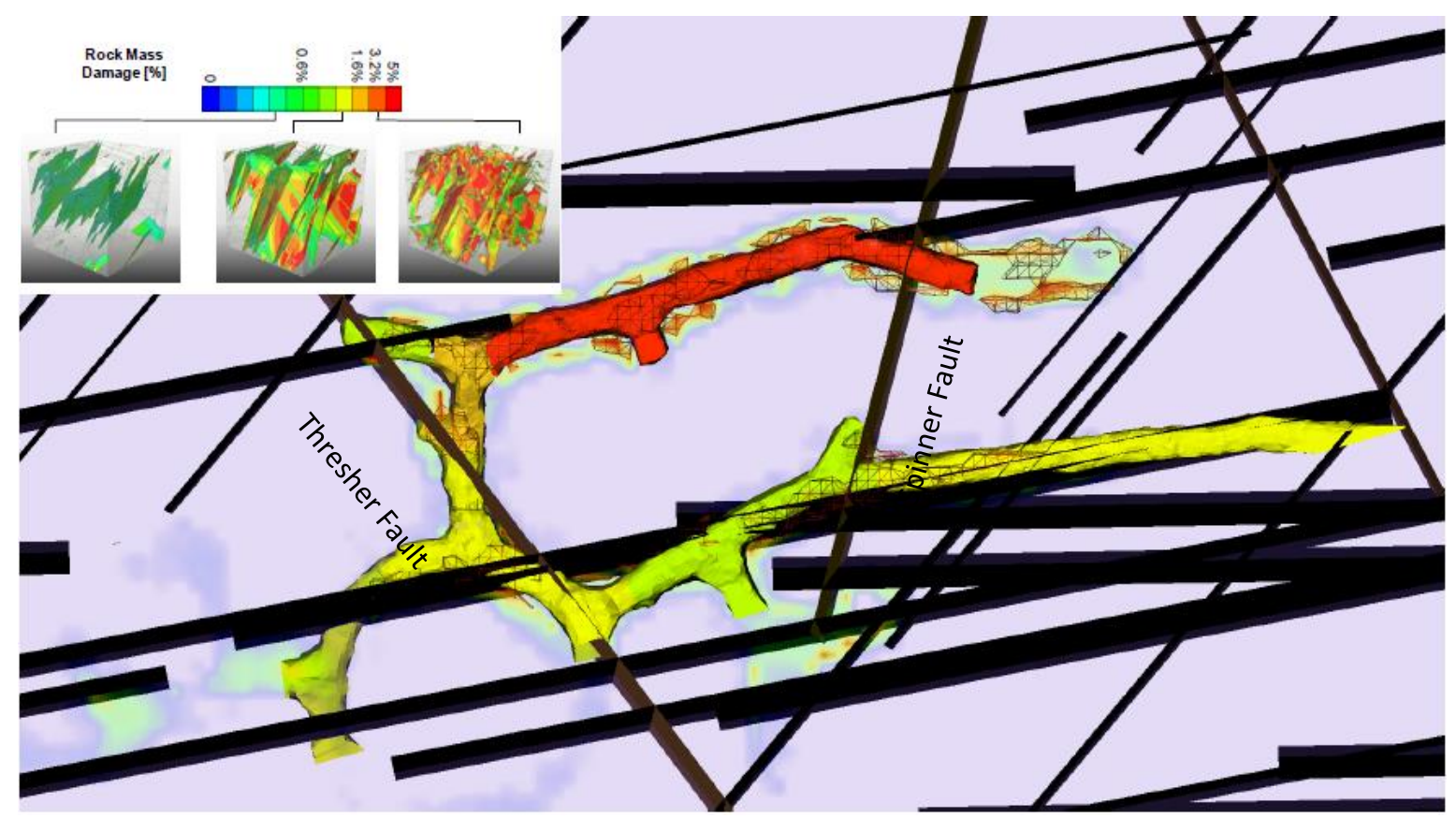

Figure 11 Simulated damage and observed damage on the 200L for the calibrated model (Jones 2016) 
Using the rock mass damage, a rate of $3.5 \%$ plastic strain was determined to correlate to approximately $1.5-2.0 \mathrm{~m}$ of yielded rock in the backs of hanging wall access development. This required significant rehabilitation including removing the yielded rock mass and re-installing an upgraded ground support system. This will be discussed further in Section 6.1. While moderate rehabilitation in the decline was indicated on rock mass damage scale by a plastic strain of $1.2 \%$. This has proved useful in predicting areas for rehabilitation prior to full-scale deformation resulting in significant rehabilitation.

Deterioration of Kim Decline below the 380 Level has gradually increased, but accelerated specifically around the 240 to 180 Levels (1,160 to $1,220 \mathrm{~m}$ depth below surface). The closure pillar forming between the 260 and 220 Levels concentrates stress through the adjacent rock mass where the decline is located. This increased stress field induces interaction between the loops of the decline and level accesses (Figure 12). Regions shown in red are areas exceeding a $\sigma_{1}$ of $120 \mathrm{MPa}$, which is approximately the yield limit for an unconfined laboratory sample (Jones 2016).

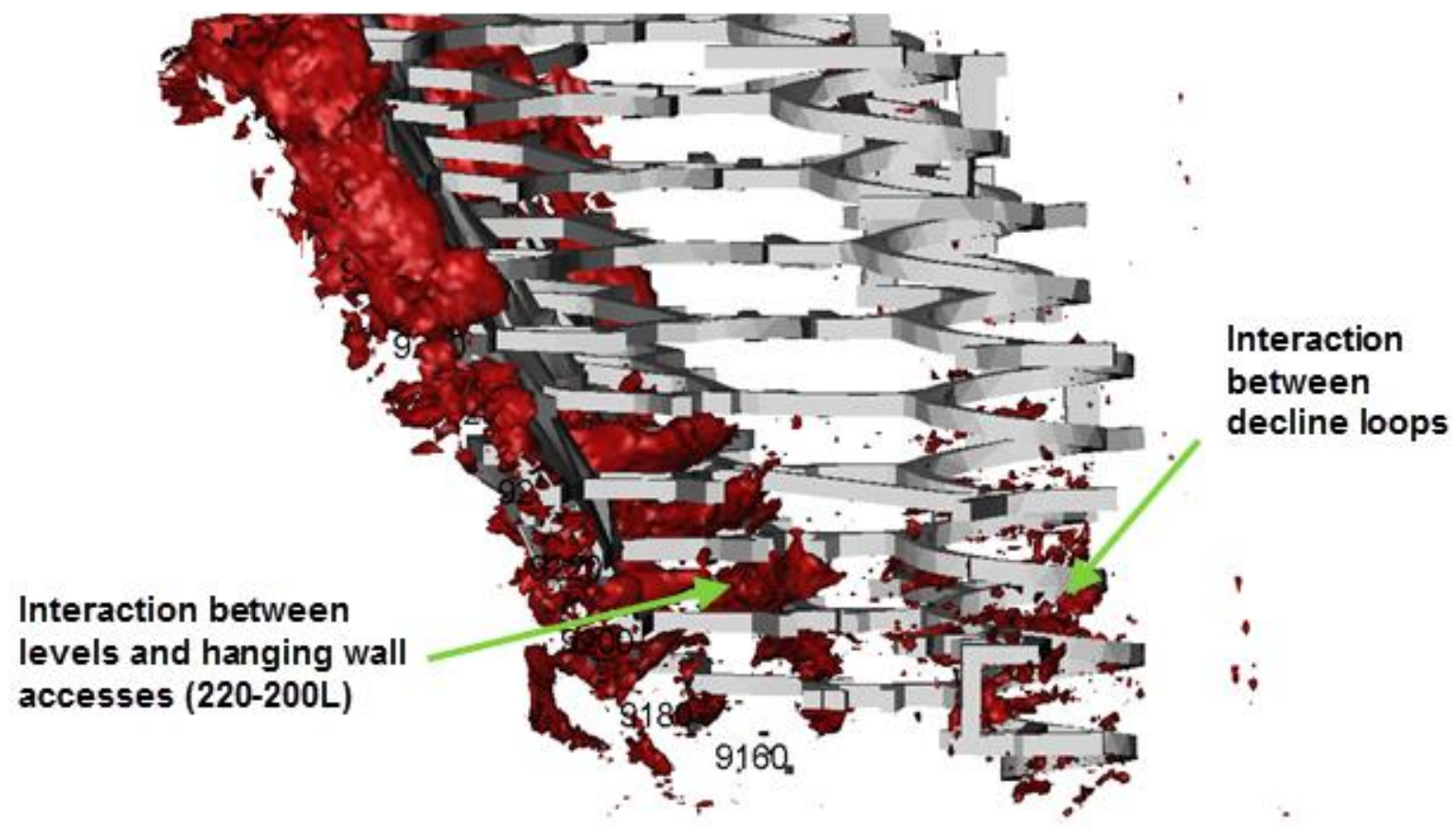

Figure 12 Looking south, showing stress concentration (exceeding sigma 1 of $120 \mathrm{MPa}$ ) in between levels and the decline

The numerical modelling was used to assess alternative mine designs with the aim to minimise rock mass damage in capital development from mining induced stress concentrations. The final changes adopted are outlined in Section 6 .

\subsection{Seismic hazard modelling}

Waroonga Underground does not have a large number of mining induced seismic events recorded compared with other high stress mines in the area. The rock mass is interpreted to be less brittle than those other mines, which allows the rock mass to adjust to stresses and distribute stored energy slowly rather than violently. Although there are relatively few events within the mine, the seismic distribution can provide insight into mining areas that have increased movement and potential future deformation.

The seismic system at Waroonga Underground is being upgraded to better capture seismic responses in the lower mining levels.

A hazard model to express seismic event frequency within the Kim levels was created based on 12 month data where all events were greater than -1.0 local magnitude. The model shows an increased rate of seismicity occurring in the south and central access drives, and the decline (Figure 13). The rate appears to 
be amplified between Thresher and Mako Faults. This initially appears to correlate well in most areas with the damage mapping and numerical model results. However, damage between Spinner and Mako Fault has been limited.

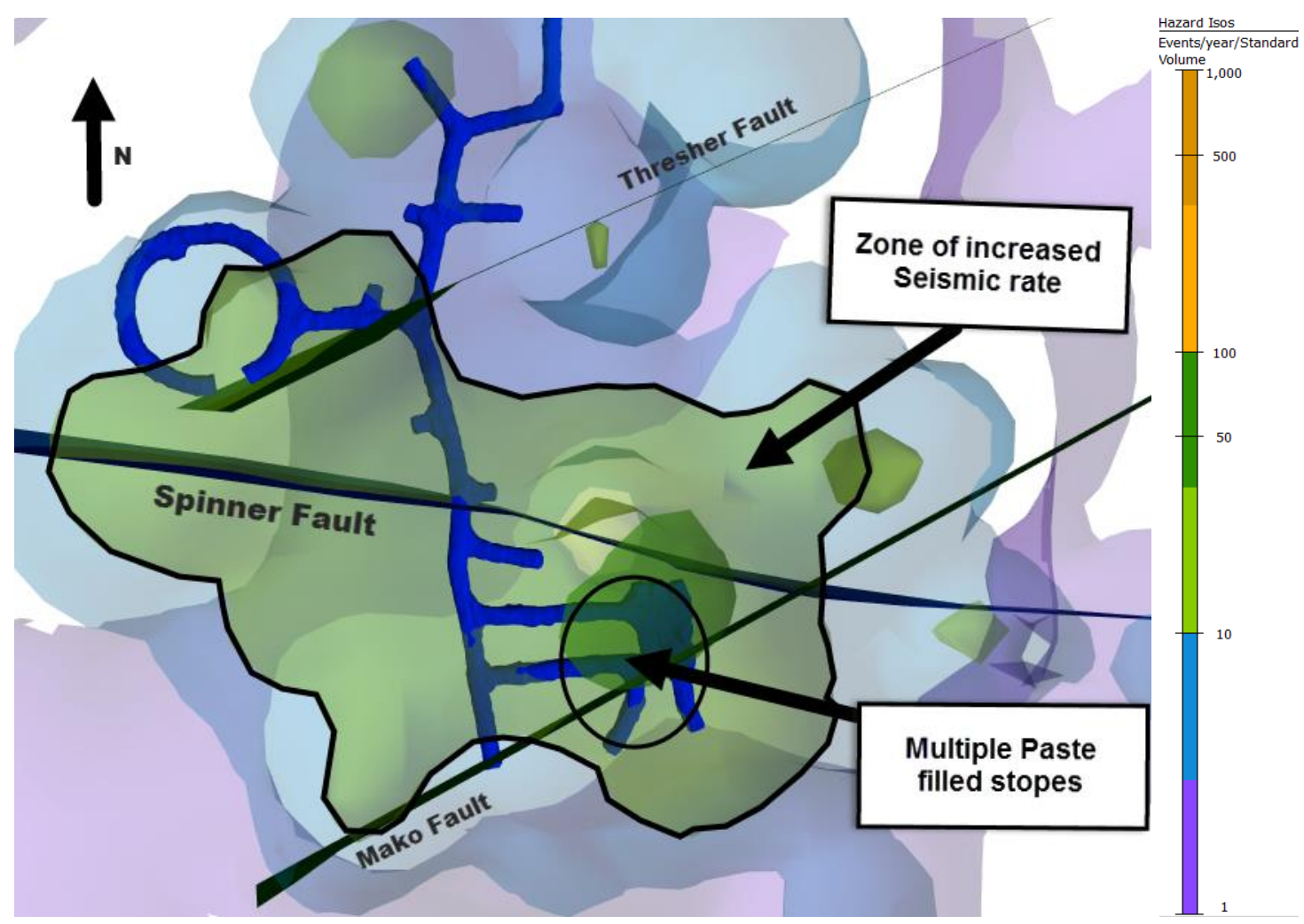

Figure 13 Seismic hazard map indicating seismic rate within Kim Lode

\section{$6 \quad$ Capital development ground control}

The observation data, internal and external modelling, proposed stoping sequence and support requirements are becoming well understood. A set of practices were implemented into managing the long-term ground control of the capital development. This is detailed below:

- Level design.

- Decline design changed from 'cork screw' to a figure of eight layout.

- Level spacings need to be increased to $25 \mathrm{~m}$.

- Drives parallel to the dominant bedding should be avoided or kept to a minimum.

- Intersection and pillars must not be designed where expected or mapped fault structures intersect.

- The capital development is to maintain greater than $100 \mathrm{~m}$ stand-off from the orezone, moved to the north and away from nearby fault structures.

- Stope extraction.

- Phase out the ' $M$ ' sequence to move to end retreat sequence for Kim Lode below 180 Level $(1,220 \mathrm{~m}$ depth below surface $)$.

- A $45^{\circ}$ stope front between levels is to be maintained wherever possible so as not to unnecessarily load and concentrate stress the level below.

- Stopes are not to be left idle, paste filling should occur as soon as possible after bogging the stope clean. 
- Ground support.

- All existing support in capital access areas is to be upgraded (refer to Section 6.1).

- Future development parallel to the bedding will be supported to withstand higher deformation floor to floor.

- Increased backs support capacity is to be provided to future development perpendicular to bedding.

- All brows are to be supported with cable bolts.

\subsection{Support upgrades}

Based on the Levkovitch Reusch (elasto-plastic) model conducted by Beck Engineering Pty Ltd (Jones 2016), it was determined the initial ground support designs within capital development will not be able to withstand the additional stress re-distributions that will occur as stoping progresses. It is recommended the support system should be upgraded to withstand and delay the onset of deformation.

It has been recommended to use a two stage support system. This system will provide initial confinement (for minor rock mass damage) during the development stage, and will allow for high deformational capacity (extensive rock mass damage/convergence) when stoping begins.

The use of $2.4 \mathrm{~m} 47 \mathrm{~mm}$ ungrouted hybrid bolts was determined to be beneficial within the support system. These bolts allow for significant displacement (up to $200 \mathrm{~mm}$ ) of the plate before the mechanism locks up. This ground support element combines high deformational capacity with typical pull-out resistance. The installation of $6 \mathrm{~m}$ twin strand $50 \mathrm{t}$ fully grouted cable bolts along with the hybrid bolts, become the preferred component of the primary ground support in high deformation conditions where large displacements are expected.

The use of $2.4 \mathrm{~m}$ spirol bolts (modified split set with $20 \mathrm{t}$ capacity) in the lower walls will be installed to pin larger slabs in place and reduce the loading that could occur on the hybrid bolts further up the walls. Both these rock reinforcement types will be in addition to fibrecrete floor to floor and mesh to $1.8 \mathrm{~m}$ above the floor (to avoid bogger damage). The previous and upgraded ground support scheme is presented in Figure 14.

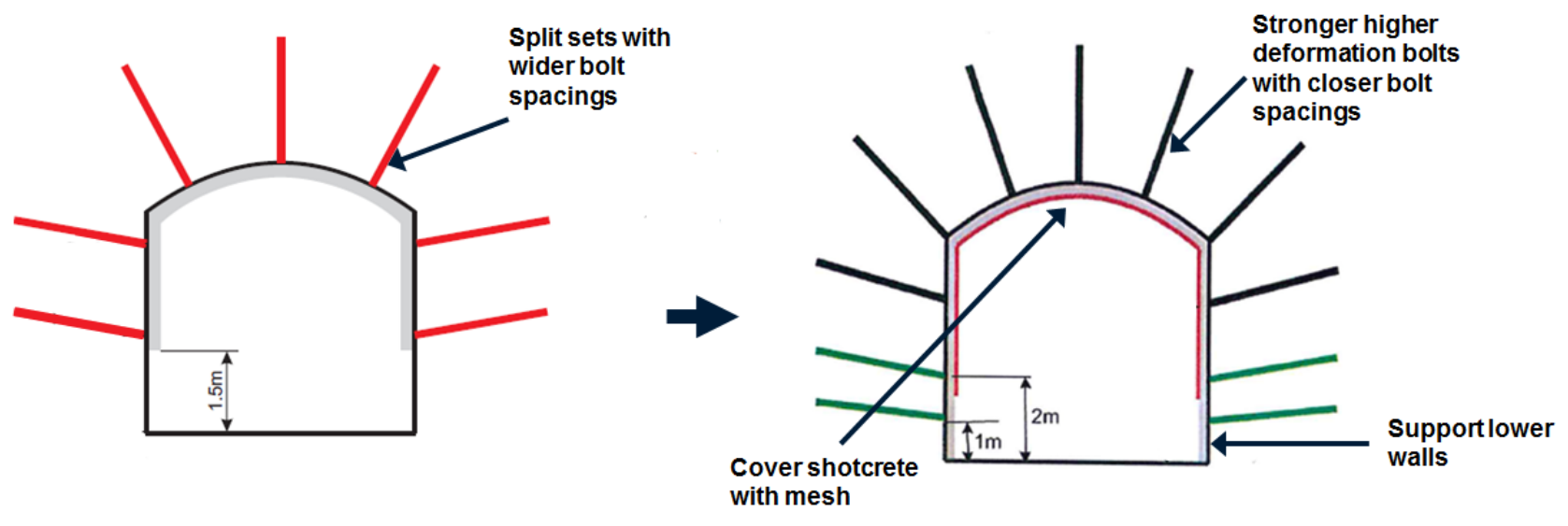

Figure 14 Premise behind ground support upgrades: (left) initial versus (right) new

The upgraded primary support system in high deformation areas comprises of: $32 \mathrm{MPa} 500 \mathrm{~J}$ fibrecrete sprayed from floor to floor at $50 \mathrm{~mm}$ thickness, mesh overlain across the backs and walls down to $2.0 \mathrm{~m}$ above the floor, $2.4 \mathrm{~m} 47 \mathrm{~mm}$ hybrid bolts installed across the backs and upper walls, and $2.4 \mathrm{~mm} 47 \mathrm{~mm}$ spirol bolts installed in the lower walls (below $2.0 \mathrm{~m}$ ). The cable bolts are installed in addition during a second pass of installation.

Depending on the orientation of the drive relative to the bedding and the deformation expectations from modelling results, ground support will also be complimented with $6 \mathrm{~m}$ cable bolts in the backs and walls. This is to ensure that the support is anchored into competent ground as deformation begins to take effect. 


\section{Further work}

The geotechnical department, at Gold Fields Australia, is in the process of implementing laser scanning of development for convergence monitoring, whereby the latest scan is compared to the previous scan to determine the change. The convergence monitoring data will be used for ongoing ground support design analysis and calibration of the numerical model.

\section{Conclusion}

As a better understanding of the observation data, numerical modelling and support requirements has developed at Waroonga Underground, a set of practices were implemented into managing the long-term ground control of the capital development.

The use of damage mapping helped identify areas requiring upgraded ground support, leading to a proactive approach to ground control. Combined with the numerical modelling and underground observations, this become a powerful geotechnical tool to identify potential high deformation areas following stoping and provide rehabilitation priorities. This information has also driven changes in capital development designs at depth, ground support standards and stope sequences, which will assist with the management of deformation.

\section{Acknowledgement}

The authors would like to thank the previous work conducted by Charlotte Woolley and Peter Andrews, and Gold Fields Australia for allowing the publication of this work.

\section{References}

Jones, E 2016, Kim lode LOM deformation \& stability assessment, report, Beck Engineering Pty Ltd.

Hadjigeorgiou, J, Karampinos, E, Turcotte, P, \& Mercier-Langevin, F 2013, 'Assessment of the influence of drift orientation on observed levels of squeezing in hard rock mines', in Y Potvin \& B Brady (eds), Proceedings of the Seventh International Symposium on Ground Support in Mining and Underground Construction, Australian Centre for Geomechanics, Perth, pp. 109-118.

Sandy, MP, Gibson, W \& Gaudreau, D 2007, 'Canadian and Australian ground support practices in high deformation environments', in Y Potvin (ed.), Proceedings of the Fourth International Seminar on Deep and High Stress Mining, Australian Centre for Geomechanics, Perth, pp. 297-312.

Sandy, M, Sharrock, G, Albrecht, J \& Vakili, A 2010, 'Managing the transition from low stress to high stress conditions', in P Hagan \& S Saydam (eds), Proceedings of the Second Australasian Ground Control in Mining Conference, The Australasian Institue of Mining and Metallurgy, Carlton South.

Woolley, CE \& Andrews, P 2015, 'Short-term solutions to squeezing ground at Agnew Gold Mine, WA', in Y Potvin (ed.), Proceedings of the International Seminar on Design Methods in Underground Mining, Australian Centre for Geomechanics, Perth, pp. 199-214. 